\title{
Carpometacarpal osteoarthritis of the thumb
}

\author{
Yu Kit Li MD, Colin P. White MD
}

The carpometacarpal joint of the thumb is a common site of osteoarthritis

Carpometacarpal osteoarthritis is a degenerative condition of the hand that causes pain, stiffness and weakness. It is the second most common site of degenerative disease in the hand after arthritis of the distal interphalangeal joints. ${ }^{1}$ Risk factors for carpometacarpal osteoarthritis of the thumb include being female, middle age, previous trauma, repetitive use and inflammatory joint disease. ${ }^{1}$ Lifetime prevalence of this condition approaches $10 \%$. $^{2}$

The differential diagnosis should include other causes of radialsided wrist pain

The presentation of this condition can mimic that of a ganglion, ruptured tendon, carpal fracture, carpal instability, De Quervain's tenosynovitis, trigger thumb, a torn ulnar collateral ligament and tendinitis of the flexor carpi radialis. ${ }^{1,2}$ Findings that suggest an alternative diagnosis include deformity of the back of the wrist, limited or painful movement of the wrist, swelling or hematoma, a positive result on the Finklestein test, locking during flexion, ligamentous laxity and lack of palpable flexor or extensor tendons when assessing range of motion.

\section{Helpful patient resources}

- www.mayoclinic.com/health/thumb -arthritis/DS00703

- http://orthoinfo.aaos.org/topic.cfm ?topic $=$ A00210

\section{Radiographic examination and the grind test aid diagnosis}

Anterior-posterior, lateral and oblique radiographic views of the thumb aid in confirming the diagnosis. ${ }^{1}$ Findings consistent with osteoarthritis include narrowing of the joint space and osteophytes, in addition to subchondral sclerosis and cysts, which can be used to stage disease using the Eaton and Littler classification. ${ }^{2}$ In late-stage disease, radiographs show degenerative changes in the scaphotrapezial joint and a "zigzag" deformity (Appendix 1, available at www .cmaj.ca/lookup/suppl/doi:10.1503/cmaj.111444/-/DC1). ${ }^{1,2}$ The grind test (axial loading and rotation of the thumb) is a provocative manoeuvre used to test for the condition. Although a positive result is highly suggestive of disease (specificity $80 \%-93 \%$ ), a negative result does not rule it out (sensitivity $42 \%-53 \%$ ). ${ }^{3}$

\section{Conservative therapy can relieve symptoms for patients with early- stage disease}

Initial options for pain relief include rest, modifying activities, physiotherapy and taking anti-inflammatory medications. ${ }^{1,2,4}$ Intra-articular injection of corticosteroids, followed by a short course of splinting ( $3 \mathrm{wk}$ ), has been shown to provide long-term relief from pain (> $20 \mathrm{mo}$ ) for patients in early stage disease. $^{4}$

\section{References}

1. Batra S, Kanvinde R. Osteoarthritis of the thumb trapeziometacarpal joint. Orthopaedics and Trauma 2007;21:135-44.

2. Cook GS, Lalonde DH. MOC-PSSM CME article: Management of thumb carpometacarpal joint arthritis. Plast Reconstr Surg 2008;121:1-9.

3. Merritt MM, Roddey TS, Costello C, et al. Diagnostic value of clinical grind test for carpometa carpal osteoarthritis of the thumb. J Hand Ther 2010;23:261-7, quiz 8.

4. Day CS, Gelberman R, Patel AA, et al. Basal joint osteoarthritis of the thumb: a prospective trial of steroid injection and splinting. J Hand Surg Am 2004;29:247-51

5. García-Mas R, Sole Molins X. Partial trapeziectomy with ligament reconstruction - tendon interposition in thumb carpometacarpal osteoarthritis. A study of 112 cases. Chir Main 2009;28:230-8.
The principal goals of surgery are relieving pain and restoring function

Surgical treatment for osteoarthritis of the thumb is indicated for severe disease (defined by radiographic evidence and pain that persists despite conservative therapy). ${ }^{2}$ The carpometacarpal joint of the thumb is the most common site in the hand for which surgery is sought. ${ }^{1}$ Although most patients report a high degree of relief postoperatively, thumb strength is expected to decrease from preoperative values. ${ }^{5}$ Function is restored primarily through pain-free use of the thumb.

\section{Competing interests: None declared.}

This article has been peer reviewed.

Affiliation: From the Division of Plastic Surgery, Department of Surgery, McMaster University, Hamilton, Ont.

Correspondence to: $\mathrm{Yu}$ Kit $\mathrm{Li}$, yukit.li@medportal.ca

CMAJ 2013. DOI:10.1503/cmaj.111444 